\title{
Sustainable land and water management of River Oases along the Tarim River
}

\author{
Markus Disse \\ Chair of Hydrology and River Basin Management, Technical University of Munich (TUM), \\ 80333 Munich, Germany \\ Correspondence to: Markus Disse (markus.disse@tum.de) \\ Published: 12 May 2016
}

\begin{abstract}
The Tarim Basin in Xinjiang province in northwest China is characterized by a hyper arid climate. Climate change and a strong increase in agricultural land use are major challenges for sustainable water management. The largest competition for water resources exists between irrigated fields and natural riparian vegetation, which is dependent on seasonal flooding of the Tarim River. In addition to numerous water management measures implemented by the Chinese government, the Sino-German project SuMaRiO (Sustainable Management of River Oases along the Tarim River) provided a decision support system based on ecosystem services for the Chinese stakeholders. This tool will help to implement sustainable land and water management measures in the next 5-year plan.
\end{abstract}

\section{Project overview}

In consequence of the rapid economic development in China, the cotton production in the Xinjiang Autonomous Region has risen sharply in recent decades. The farming industry and the natural vegetation are thus in conflict over the very limited water resources.

\subsection{The Tarim Basin}

The Tarim Basin is an intercontinental region with extreme arid climate. The Tarim River gets its water mainly from the meltwater from snow and glaciers of the surrounding mountains (see Fig. 1). In the Tarim Basin the annual rainfall can reach about $70 \mathrm{~mm}$ and the potential evaporation is about $2000 \mathrm{~mm}_{\text {year }}{ }^{-1}$. People settled already in ancient times along the Tarim River, resulting in a series of oases forming the historical Silk Road. Today the oases are greatly increased mainly by cotton fields. The character of the landscape and the socio-economic situation of the population has changed considerably. Due to the high water demand of irrigation farming more and more water has been extracted from the river and the groundwater. This led to the fact that the Tarim River no longer reached its terminal lake (Taitema Lake) and dried up halfway. Secondly, the water is contami- nated with salt, fertilizers and pesticides, which impacts not only on the floodplain forests and river ecology but also on human health.

\subsection{SuMaRiO}

Large areas of agricultural soils have become unusable through salinization, the river lining flood-plain vegetation has vastly receded, and important Ecosystem Functions/Ecosystem Services (ESF/ESS) such as providing uncontaminated irrigation water or attenuating dust and sand storms by vegetation have been severely decreased, or completely lost. The BMBF (German Federal Ministry of Education and Research) funded the interdisciplinary project SuMaRiO which aims to consider the complete land and water management system with its ESS/ESF in an integrated way taking into account diverse problem perceptions of the stakeholders.

The overall goal of SuMaRiO is to support oasis management along the Tarim River under conditions of climatic and societal changes by:

- developing methods for analysing ESF/ESS, and integrating them into land and water management of oases areas and floodplain forests; 


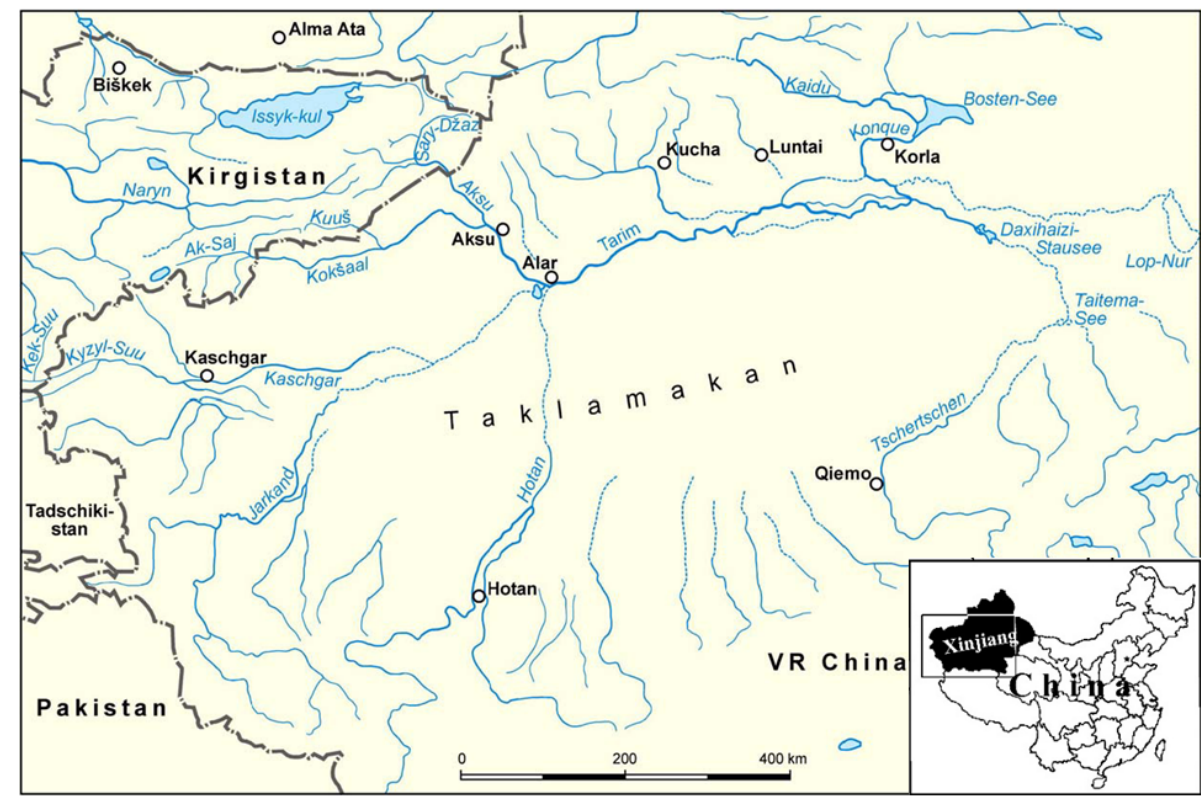

Figure 1. Location of the study area in Xinjiang/China.

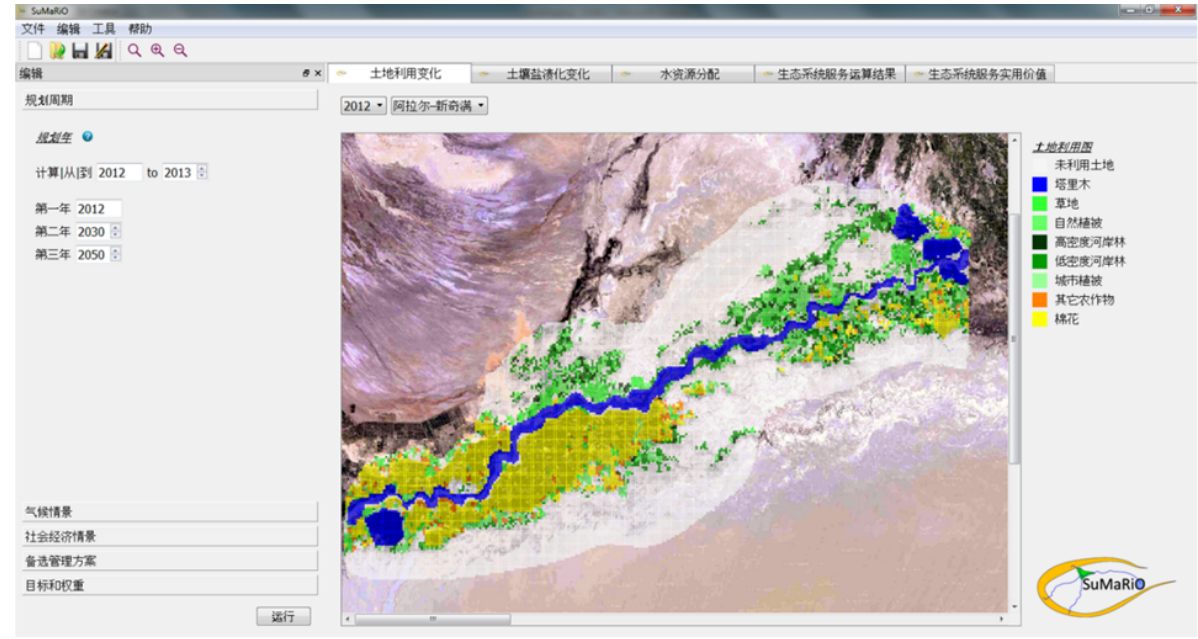

Figure 2. Exemplary representation of the Chinese user interface of the Decision Support System (DSS).

- involving stakeholders in the research process to integrate their knowledge and problem perceptions into the scientific process;

- developing tools with Chinese decision makers that demonstrate the ecological and socio-economic consequences of their decisions in a changing world;

- introducing participatory approaches into the development of sustainable management structures;

- jointly identifying options for optimizing economic, ecological, and societal utilities; and
- implementation of sustainable land management strategies.

This article focuses on the hydrological modelling of the water balance and the structure of the decision support system (DSS). The implementation phase will begin in 2016 when the Chinese partners will get training in the use of the developed tools.

\subsection{Decision Support System (DSS) as a water and land management tool for the Tarim Basin}

The demand for irrigation water for cotton cultivation exceeds especially in spring the discharge of the Tarim River. 


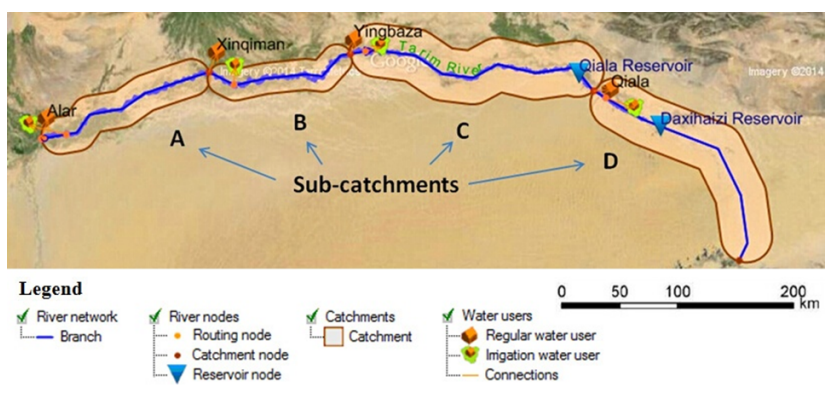

Figure 3. Aggregated sub-basins of the model MIKE HYDRO.

Therefore, the poplar forests (tugai) have declined significantly in recent decades and are endangered in the lower river. The so-called "green corridor" represents a (vitally) important barrier to the silting of the desert oases and the adjacent infrastructure. Other ecosystem services of the Tugai forests are biodiversity, climate regulation, carbon sink and tourism.

A decision support system (DSS) was designed and programmed to evaluate and compare different ESS indicators. The Potsdam Institute for Climate Impact Research (PIK) simulated different climate scenarios with the model SWIM and provided the discharge of Aksu, Hotan and Yarkant Rivers to their confluence in Alar (see Fig. 1) as input for the DSS. The user of the DSS can select one out of four climate scenarios and thus initiate the simulation for the corresponding hydrograph and associated evapotranspiration along the Tarim River.

To bridge the gap between science and practice, the DSS must be understood, accepted and used by Chinese stakeholders and decision makers. Therefore, the graphical user interface should be intuitive to use and in addition to English also available in Chinese (see Fig. 2).

\section{Hydrological modelling}

The study area for the water allocation model MIKE HYDRO begins in Alar and ends on Taitema Lake (see Fig. 1). MIKE HYDRO is a deterministic, semi-distributive and physically based model system that can be used for the simulation of water consumption, actual evapotranspiration, irrigation management, crop yields and plant growth. For large-scale modelling, the Tarim River has been divided into four main sections, which were marked by discharge gauges (see Fig. 3): Alar Xinqiman (A), Xinqiman-Yingbaza (B), Yingbaza-Qiala (C), and Qiala-Taitema Lake (D). In each of these sub-regions, the results are aggregated for water consumption and biomass production and passed to the DSS.

After calibration of MIKE HYDRO various water-saving scenarios were simulated (Yu et al., 2015). Important results are shown in Fig. 4 and Table 1. From Fig. 4 it is obvious that the plant available water, which can be determined from usable field capacity and effective root length for most agri-

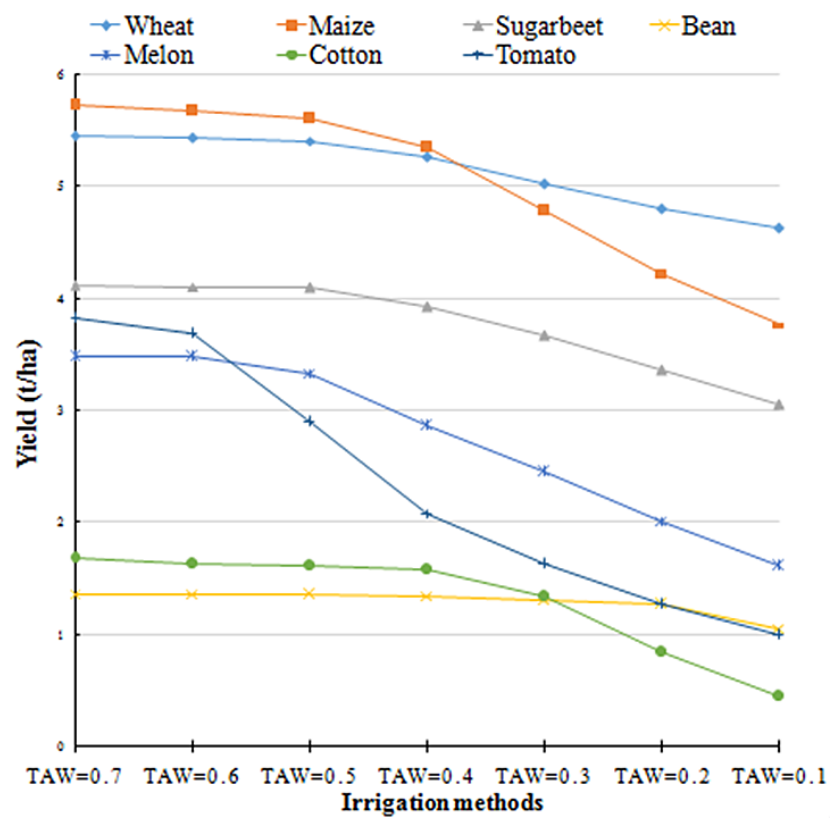

Figure 4. Irrigation scenarios depending on the plant available water (TAW). The average crop yield are based on a 3-year simulation period (see also Doorenbos and Kassam, 1979).

Table 1. Results of five different scenarios DIUM (Drip Irrigation Under Mulch) with $\mathrm{SL}=$ spray loss, WF $=$ Wetting Fraction, $\mathrm{WS}=$ Water Saving.

\begin{tabular}{rrrr}
\hline$\%$ DIUM & $\%$ SL & $\%$ WF & $\%$ WS \\
\hline 10 & 46 & 91 & 6 \\
30 & 38 & 73 & 17 \\
50 & 30 & 55 & 25 \\
70 & 22 & 37 & 32 \\
100 & 10 & 10 & 40 \\
\hline
\end{tabular}

cultural crops must not be filled up to $70 \%$. For cotton a deficit irrigation up to about $40 \%$ TAW is acceptable without having severe yield losses. Therefore, this type of irrigation should be promoted in Xinjiang. A second way to save water for agriculture is the irrigation technology "drip irrigation under plastic mulch" (DIUM). Table 1 shows a water saving potential of up to $40 \%$, mainly due to prevention of (unproductive) soil evaporation by covering the soil with plastic wrap ("mulch").

The results of MIKE HYDRO - supplemented by scenarios of water losses along irrigation canals - were finally passed as simplified regression relationships to the DSS. In this way it could be ensured that the impact of land management scenarios is based on a solid model and data base. The loss of accuracy by the transfer of the model results to the DSS are negligible. If necessary, additional MIKE HYDRO scenario calculations can supplement the database of the DSS. 


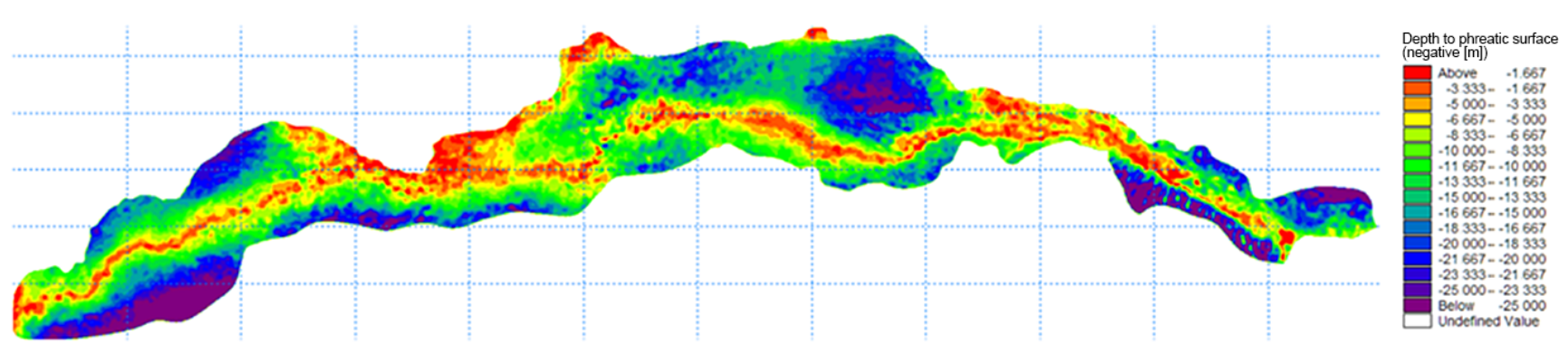

Figure 5. Simulated groundwater levels along the Tarim.

Table 2. ESS Indicators.

\begin{tabular}{|c|c|c|}
\hline Ecosystem & Ecosystem Service & ESS Indicator \\
\hline Agriculture & Provisioning services & $\begin{array}{l}\text { Cotton Production [million } \mathrm{t} \text { ] } \\
\text { Production of fruits [million } \mathrm{t} \text { ] } \\
\text { Production of other crops [million } \mathrm{t} \text { ] } \\
\text { Income of the farmer [million CNY] }\end{array}$ \\
\hline Riparian Forest & $\begin{array}{l}\text { Provisioning services } \\
\text { Regulating Service }\end{array}$ & $\begin{array}{l}\text { Biomass production [million } \mathrm{t} \text { ] } \\
\text { Dust filtering through floodplain forests [kg] } \\
\text { Control of sand drift by riparian forests [million } \mathrm{t} \text { ] } \\
\text { Wind control [damping in } \% \text { in } 2 \mathrm{~m} \text { height] } \\
\text { Carbon storage [million } \mathrm{t} \text { ] } \\
\text { Main species [number] }\end{array}$ \\
\hline Grassland & Provisioning services & $\begin{array}{l}\text { Production of Apocynum [million } \mathrm{t}] \\
\text { Production of reeds }[\mathrm{t}]\end{array}$ \\
\hline
\end{tabular}

Table 3. Socio-economic indicators in the DSS.

\begin{tabular}{ll}
\hline Production costs for cotton, fruits and other agricultural products & {$\left[\mathrm{CNY} \mathrm{ha}^{-1}\right]$} \\
\hline Sales revenue for cotton, fruits and other agricultural products & {$\left[\mathrm{CNY} \mathrm{ha}^{-1}\right]$} \\
\hline
\end{tabular}

Table 4. Management indicators for the design of management measures in the DSS.

\begin{tabular}{ll}
\hline Proportion of drip irrigation to the entire irrigation area & {$[\%]$} \\
\hline Subsidy for drip irrigation & {$\left[\mathrm{CNY} \mathrm{ha}^{-1}\right]$} \\
\hline Proportion of water allocation for households and commercial/industrial & {$[\%]$} \\
\hline Proportion of the flooded area for natural vegetation & {$[\%]$} \\
\hline
\end{tabular}

Table 5. Land use types.

\begin{tabular}{lll}
\hline Fallow land & Grass & Reed \\
\hline $\begin{array}{l}\text { Light riparian vegetation } \\
\text { Cotton }\end{array}$ & $\begin{array}{l}\text { Dense riparian vegetation } \\
\text { other agricultural cash crops }\end{array}$ & Urban vegetation \\
\hline
\end{tabular}

Since the effect of the respective scenarios has a direct impact on the groundwater situation along the Tarim River, the internal calculation of groundwater levels is indispensable (Keilholz et al., 2015). The DSS should be usable for sub- sequent users without a license, so that the software can be easily distributed and freely accessed to both public authorities and for educational institutions. 


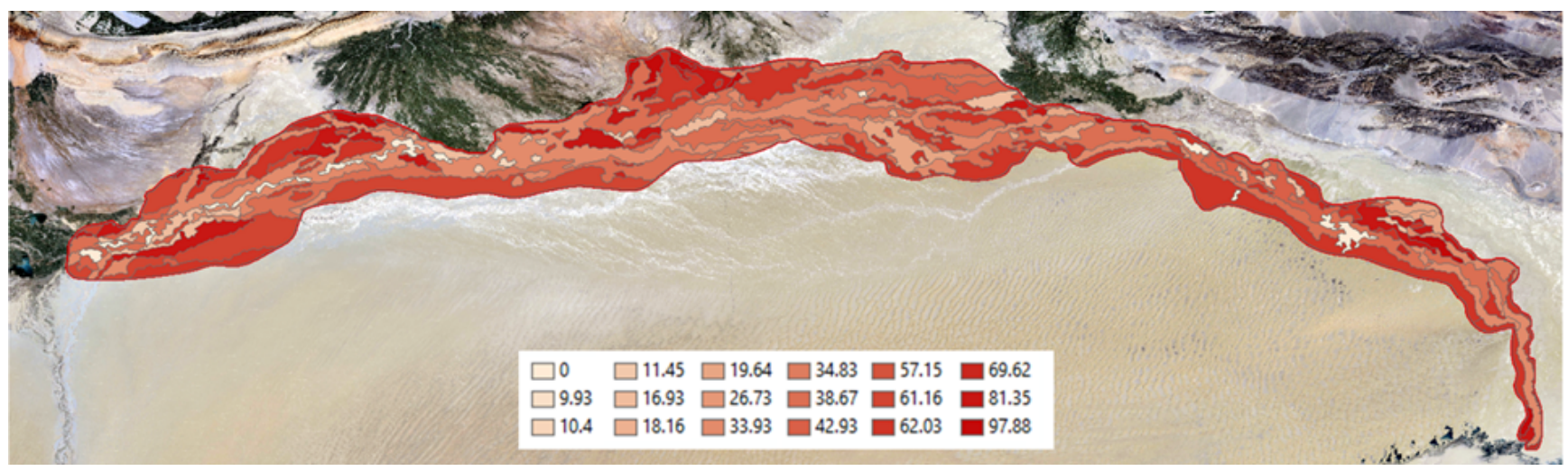

Figure 6. Distribution of the salt concentration in the soil in $\mathrm{ECe}\left[\mathrm{mS} \mathrm{cm}^{-1}\right]$.

One common open-source code for simulating groundwater movement is the model MODFLOW. Due to its modular structure and the grid-based calculation, it was used for calculating the groundwater distribution. The resulting groundwater levels of MODFLOW due to artificial flooding of the Lower Tarim River and other management practices are coupled with the DSS with a spatial resolution of $500 \mathrm{~m} \times 500 \mathrm{~m}$ (see Fig. 5).

\section{Implementation of the Decision Support System (DSS)}

Based on these two models and the contribution of the other work blocks within the project, the DSS could be designed and implemented.

The DSS is an indicator based tool that enables stakeholders and decision-makers to evaluate the consequences of their actions. Among selected scenarios of future climate and socio-economic development, the impact of planned management measures is determined by quantitative and semiquantitative methods based on ESS indicators (Table 2). All indicators were conducted by SuMaRiO workshops (DSS workshops, stakeholder workshops) and has been classified as relevant. The following Tables 3-5 show examples of the required input data (i.e. management data) which formed the core for the evaluation of the management alternatives.

The impact on the ESS indicators and the available discharge along the Tarim River for each scenario year is calculated with the help of multivariate functions, lookup tables or fuzzy rules. The output is presented in tables and graphs. Based on these results and the objectives assigned to the ESS indicators by the user, a degree of target achievement between 0 and 1 is calculated, indicating the relative target fulfilment by each measure for each ESS indicator. Additionally, the DSS displays for each year to what extent there was an improvement/deterioration of the utility value compared to the first planning year. Based on this differentiated outputs the trade-offs between the ESS indicators can be analysed.
Furthermore, it calculates the change in land use and soil salinization for each grid cell for the last year of the simulated time period (see Fig. 6).

The DSS with the coupled MODFLOW groundwater model will be delivered to the Chinese partners free of charge. In the coming 5-year plan (starting 2016) three pilot areas have been defined in Xinjiang. The DSS will be tested and further developed in these areas under the supervision of the Chinese Academy of Science (Xinjiang Institute of Ecology and Geography). Generally, the DSS is applicable for other regions, too, and is free available on request.

Acknowledgements. We thank the German Federal Ministry of Education and Research for the funding of the SuMaRiO consortium as part of the Sustainable Land Management Program (FKZ: 01LL0918L). We also thank our partners from the Xinjiang Institute of Ecology and Geography, Chinese Academy of Sciences who helped with our fieldwork and provided the basic data and information. And of course all the other Chinese and German SuMaRiO colleagues should be mentioned for SuMaRiO works only as a team.

\section{References}

Doorenbos, J. and Kassam, A. H.: Yield Response to Water, Irrigation and Drainage Paper, FAO, Rome, Italy, 33, p. 257, 1979.

Keilholz, P., Disse, M., and Halik, Ü.: Effects of Land Use and Climate Change on Groundwater and Ecosystems at the Middle Reaches of the Tarim River Using the MIKE SHE Integrated Hydrological Model, Water, 7, 3040-3056, doi:10.3390/w7063040, 2015.

Yu, Y., Disse, M., Yu, R., Yu, G., Sun, L., Huttner, P., and Rumbaur, C.: Large-Scale Hydrological Modeling and DecisionMaking for Agricultural Water Consumption and Allocation in the Main Stem Tarim River, China, Water, 7, 2821-2839, doi:10.3390/w7062821, 2015. 